\title{
THE RESOLUTION OF THE HEBERDEN-PARRY CONTROVERSY
}

by

\author{
BRIAN LIVESLEY*
}

There is a simple, and, so to speak, natural means of broaching these great and important questions: it is to inquire as to how, in the course of the progressive development of scientific culture, they have become known and how they have been settled; in this way history becomes a means of criticism. ${ }^{1}$

Jean-Martin Charcot (1825-1893).

\section{INTRODUCTION}

During the last 200 years there has been no significant improvement upon William Heberden's original description of the symptoms of angina pectoris. ${ }^{2}$ Although he was unaware of the aetiology of the condition, so relatively quickly did his account become established that C. H. Parry's controversial attempt, thirty years later; to point out " . . . the mistakes of some of my medical brethren, in their nosological judgement of this disease ....", did not find its proper place..$^{3}$ Moreover, Parry's important concept of the syncope anginosa became progressively misinterpreted, neglected and finally forgotten. Indeed, the syncope anginosa is not thought to be relevant to medical practice today and Parry's work in this field is used as a reference only because it describes Jenner's original discovery of obstructive coronary arterial disease. However, as a result of personal observations made using radiotelemetric electrocardiography ${ }^{4}$ and atrial-pacing coronary-sinus lactate studies 5 in the investigation of patients with ischaemic heart disease, an explanation can be put forward which not only underlines the importance of Parry's work but also resolves the Heberden-Parry controversy. We can now show that, in the light of present-day knowledge, both Heberden and Parry described conditions which are at the opposite ends of the clinical spectrum of ischaemic heart disease. Furthermore, we can understand not only how Parry's concept gradually became neglected but also how the Heberden-Parry controversy could have been resolved by earlier reference to the symptoms of their famous contemporary. John Hunter had both the angina pectoris of William Heberden and the syncope anginosa of Caleb Hillier Parry.

ANGINA PECTORIS AND SYNCOPE ANGINOSA

A brief explanation of our present understanding of the pathophysiological processes involved in the aetiology of angina pectoris is essential to the resolution of the problem.

It is now well established that myocardial oxygen consumption is linearly related to heart rate and that the rise in rate occurring during exercise is associated with an increase in coronary blood flow which makes more oxygen available for the increased

*Brian Livesley, M.B., M.R.C.P., The Department of Medical History, King's College Hospital, London, S.E.5. 


\section{The resolution of the Heberden-Parry controversy}

requirements of the myocardium. However, the presence of coronary atherosclerosis impedes coronary arterial blood flow and in patients with significant obstructive coronary arterial disease, at a certain level of increased heart rate, resulting from either physical exertion or rapid atrial pacing, the myocardial oxygen requirement exceeds the supply. This results in ischaemia of the affected myocardium with the development of the classical symptoms of angina pectoris. 6,7 These symptoms resolve when the patient rests because the heart rate and therefore the myocardial oxygen requirement falls to a level which can be supplied through the diseased coronary arteries. The clinical description of this series of events is best described by Heberden:

There is a disorder of the breast, marked with strong and peculiar symptoms, considerable for the kind of danger belonging to it, and not extremely rare, of which I do not recollect any mention among medical authors. The seat of it, and sense of strangling and anxiety with which it is attended, may make it not improperly be called angina pectoris. ... .

The os sterni is usually pointed to as the seat of this malady, but it seems sometimes as if it was under the lower part of it, and at other times under the middle or upper part, but always inclining more to the left side, and sometimes there is joined with it a pain about the middle of the left arm. Those, who are afflicted with it, are seized, while they are walking, and more particularly when they walk soon after eating, with a painful and most disagreeable sensation in the breast, which seems as if it would take their life away, if it were to increase or to continue: the moment they stand still, all this uneasiness vanishes....

It would appear therefore, that the patients described by William Heberden had severe obstructive coronary arterial disease with myocardial ischaemia, and thereby angina pectoris, being precipitated by a tachycardia induced by exertion. ${ }^{\circ}$

During my investigation of more than 120 patients, the sophisticated technique of rapid atrial-pacing coronary-sinus lactate studies ${ }^{10}$ did not confirm the diagnosis of angina pectoris in a few patients whose symptoms were believed to be typical of ischaemic heart disease. This was at first not understood until it was realized that these patients did not experience attacks of angina when the heart rate was increased, either by a rigorous exercise tolerance test ${ }^{11}$ or by rapid atrial-pacing. However, these patients did experience typical symptoms during episodes of bradycardia which occurred at rest. In order to understand this it is important first to appreciate that myocardial contractility is directly related to heart rate and this phenomenon although first described in the frog's heart ${ }^{12}$ has since been described in man. ${ }^{13}$ At slow heart rates myocardial contractility, and thereby the rate of arterial blood flow, is reduced resulting in tissue hypoperfusion which precipitates symptoms due to both cerebral and myocardial ischaemia. If the progression of events is not reversed then death occurs.

The classical Stokes-Adams attack is a well-recognized, extreme example of this phenomenon. The aetiology of spontaneous bradycardiac episodes which occur while the patient is resting is not completely clear. In some patients the condition can be familial. ${ }^{14}$

At this opposite end of the clinical spectrum of established ischaemic heart disease, spontaneous attacks of angina occurring at rest are due, not to obstruction to coronary blood flow because of atherosclerosis, but to reduced coronary blood flow during the tissue hypoperfusion associated primarily with severe bradycardia. Furthermore, the effects of bradycardiac hypoperfusion are aggravated by minor degrees of coronary 


\section{Brian Livesley}

atheroma which alone are not sufficient to obstruct the increased blood flow occurring during a tachycardia produced by exercise. This explains why these patients do not experience tachycardiac angina on effort. Moreover, as the coronary arterial atheroma increases in quantity and thereby in functional significance, these susceptible patients develop both the bradycardiac angina at rest typical of Parry's patients and also the tachycardiac angina on effort described by Heberden. The following brief case report and the three described previously ${ }^{15}$ support this hypothesis.

In 1970, a hospital porter, aged fifty-six years, stated he had experienced attacks of "giddiness" with occasional transient unconsciousness since his 'teens. From 1966 these episodes were associated with typical anginal symptoms and after attacks, heart rates of $40-48$ beats/minute were recorded. His syncopal episodes and angina were completely relieved following the implantation of an on-demand cardiac pacemaker in 1970. He died suddenly in 1974.

Unfortunately for the clinician, the differentiation between angina on effort being due to presumed tachycardia and that at rest being due to presumed bradycardia is not always so precise for the following reasons: (1) it is well recognized that paroxysmal tachycardia can occur at rest in patients with obstructive coronary arterial disease; (2) severe bradycardia, due to disease or disorder of the specialized conducting tissue of the heart, may persist and precipitate angina during effort; (3) a few patients who have tachycardiac angina on effort can also experience symptoms due to bradycardiac attacks at rest, ${ }^{16}$ (4) some patients experience cardiac pain at rest due to repeated micro-embolization along the coronary arteries from more proximally situated atheromatous abscesses. ${ }^{17}$

Although it is possible to differentiate these conditions by radiotelemetric electrocardiography, coronary-sinus lactate studies and arteriography, it is the consideration of the differences between the classical accounts of Heberden's and Parry's angina which concerns us here. The syndrome described by Parry in 1799 in An inquiry into the symptoms and causes of the syncope anginosa, commonly called angina pectoris can be seen in perspective only if we consider first the people involved in the controversy. We must of necessity begin with William Heberden.

\section{WILLIAM HEBERDEN (1710-1801)}

It is important to note that Heberden, born in London, entered St. John's College, Cambridge, at the age of fourteen, and in 1739 received his degree of Doctor of Medicine when aged twenty-nine years. He was elected a Fellow of the Royal College of Physicians in 1746 and subsequently practised medicine in London. His later position as a leader of the medical establishment is shown by his ability to be one of the prime movers in the publication of the Medical Transactions of the Royal College of Physicians. His account of angina pectoris was published in this journal in 1772. This early account had been based upon a twenty-years' study of some twenty patients and shows how carefully his observations were made and recorded. He continued with this work and stated in his Commentaries on the history and cure of diseases, published posthumously in 1802 , that he had seen nearly 100 people with the condition. ${ }^{18} \mathrm{He}$ retired from medical practice in 1782 , seventeen years before Parry's views became known. 


\section{The resolution of the Heberden-Parry controversy}

CALEB HILLIER PARRY (1755-1822)

Parry could not expect to achieve the same eminence as Heberden in the medical establishment of his day. Fellowship of the Royal College of Physicians would not be open to him because, as the son of a Presbyterian Divine, he was by religion a dissenter. In 1773, when he left the Dissenters' Academy in Warrington, he proceeded to Edinburgh and there graduated in medicine in 1778. One year later he took up medical practice in Bath and became one of the most famous and distinguished physicians outside London. Together with Edward Jenner and a few other medical colleagues, he founded a small medico-convivial club which used to meet at The Fleece Inn, Rodborough, near Stroud. He gave original descriptions of several diseases including thyrotoxicosis but his election to the Royal Society in 1800 was the result of his work with sheep. However, it is his work on ischaemic heart disease which concerns us now and it is interesting to note that his biographers ${ }^{19,20,21}$ have paid scant attention to his concept of the syncope anginosa.

In reading his account of this condition it is apparent that, whereas Heberden was simply a clinician, Parry was a clinical pathophysiologist. By his careful choice of words Parry was determined, albeit smoothly, to put the establishment clinician in his place. Reference to only two of Parry's incisive phrases, which I have italicized, will be sufficient to illustrate his patronising attitude towards Heberden's account of the disorder.

"I think it evidently appears, that the angina pectoris is a mere case of syncope or fainting, differing from the common syncope only in being preceded by an unusual degree of anxiety or pain in the region of the heart. . . . On this principle I would then venture to insert this disease, in Dr. Cullen's Nosological System under the trivial name of SYNCOPE ANGINOSA." [my italics1 ${ }^{22}$

Heberden had based his orginal account upon the interpretation of some twenty cases. Parry's case for the syncope anginosa began with details of Jenner's discovery of disease of the coronary arteries which he then followed with detailed accounts of only three of his own patients and three previously described by Morgagni. ${ }^{23}$ To understand Parry's point of view we must first review the case reports he presented.

\section{PARRY'S CASE REPORTS}

(1) Mr. J. Bellamy, aged fifty-six years, had " . . . a violent pain in the chest . . . accompanied with a sense of stricture, difficulty of breathing, sickness and vomiting, a weak irregular pulse, pale countenance, and cold, but profuse perspiration. These symptoms continued about two hours ...." ${ }^{24}$ In March 1786, this patient began to experience typical angina on effort [Heberden's angina]. However, he subsequently developed paroxysms of pain at rest which symptom radiated from the chest to the left arm.

(2) Reverend Mr. S., aged sixty-six years, was about the year 1766 “ . . for a considerable time troubled with pain in the breast and arm . . . ${ }^{25}$ This must have occurred at rest since " . . . He was accustomed to take great exercise in walking and riding . . " ${ }^{26}$ until he fell from his horse in 1780 . Furthermore, the patient used to swing lead weights a hundred times each day! It is unlikely, therefore, that he had tachycardiac angina induced by effort. In 1786, his attacks were prolonged and a 


\section{Brian Livesley}

surgeon, Mr. Rundell, noted that the patient was “. . . . almost without pulse ..."27 during an attack but when he recovered from this attack ${ }^{28}$ the patient " . . . began to look around him with a vacant stare, was capable of speaking, and wondered why so many persons were about him ....".29

(3) Mr. M., aged seventy-seven years, experienced not only typical angina on effort but also attacks of angina at rest during which time he was " . . . without pulse ...". ${ }^{20}$

To add support to his cause, Parry quoted from two of Morgagni's cases. One, a Bolognese nun, had symptoms described as, “. . . oppression of the heart was also accompanied with slight faintness; and the pulse was always feeble, even while she was at rest . ..".31 The other, a man aged fifty-five years, had “ . . . a difficulty of breathing, which was aggravated by motion, not without a certain anguish of the heart .... The pulse was hard, rather slow. ... At length he began to be affected with faintings ..."32 and eventually died in an attack.

\section{PARRY'S HYPOTHESIS}

Parry's interpretation was that, “. . f from this relation I think it is evident that the angina pectoris is in reality a case of fainting; the syncope .... All the circumstances in the angina pectoris preceding the actual syncope are approaches towards it; and in every uncombined and recent case, like those which I have described, the patient probably dies with no other symptoms than those which shew an irrecoverable diminution of the motion of heart ..." [my italics].33

However, supported by Jenner's observations which were: “ . . . Another case [of angina pectoris] . . . fell under my care. In that, after having examined the more important parts of the heart, without finding any thing by means of which I could account either for his sudden death, or the symptoms preceding it, I was making a transverse section of the heart pretty near its base, when my knife struck against something so hard and gritty, as to notch it. I well remember looking up to the ceiling, which was old and crumbling, conceiving that some plaister [sic] had fallen down. But on further scrutiny the real case appeared: The coronaries were become bony canals. Then I began a little to suspect ....."s4

Parry went on to say, "... that a principal cause of the syncope anginosa is to be looked for in disordered coronary arteries. . .."35

His logical approach to the analysis of the few cases he had recorded is obvious when he wrote in chapter five of his book:

II. That so far as the most accurate observation has hitherto gone, the tendency to this disorder arises from mal-organization in the heart itself; which mal-organization seems to be chiefly induration of the coronary arteries [my italics].

III. That this mal-organization acts by diminishing the energy of the heart. By the energy of the heart I mean not merely the readiness, but also the degree of irritability or excitability [my italics].

IV. That the chief symptoms of the disease are the effect of blood retarded and accumulated....

V. That the cases exciting the paroxyms are those which produce this accumulation; 1. By mechanical pressure;. .... 26

VI. That, after a certain approach towards quiescence, the heart may recover its irritability, so as again to carry on the circulation in a more or less perfect degree, from the operation of the usual stimuli; but

VII. That death may at length ensue from a remediless degree of inirritability in the heart Imy italics]. ${ }^{37}$ 


\section{The resolution of the Heberden-Parry controversy}

In discussing Heberden's account Parry stated “... Dr. Heberden asserts that the pulse is, at least sometimes not disturbed by this pain, and consequently the heart is not affected by it, . . ."38 but went on to say that Heberden never felt the pulse during severe paroxysms but only during mild attacks. In his later Commentaries, published in 1802 , Heberden stated that during a fit of angina pectoris “ . . . the pulse is not quickened ..... .9 This was obviously a reply to Parry's concept of the syncope palpitans ${ }^{40}$ and also shows that Heberden did not exercise his patients to study their angina induced by effort. Parry attacked Heberden's account of angina pectoris further when he stated, “. . . There is a symptom which has occurred so frequently in the syncope anginosa, as to have much occupied the attention of physicians, some of whom have considered it as a diagnostic of that disease; I mean the pain extending from the affected part of the breast into the left arm. ... It neither constantly occurs in the syncope anginosa, nor is peculiar to that disorder; being often found to accompany violent palpitation of the heart, hydrothorax and dilation of the aorta ..."41

Paroxysmal tachycardia occurring at rest can, however, precipitate myocardial ischaemia in susceptible patients as has been discussed previously. Hydrothorax can be due to bronchogenic carcinoma which may also invade the brachial plexus and thereby produce severe pain referred to the arm. Dilatation of the aorta was probably due to syphilis in the case to which Parry referred and this was so commonly associated with aortic incompetence and angina pectoris that Allbutt believed angina arose from the aorta. ${ }^{42}$

THE MISINTERPRETATION AND EVENTUAL NEGLECT OF PARRY'S HYPOTHESIS

Unfortunately, Parry's pathophysiological interpretation of angina excluded consideration of the importance of exercise-induced tachycardia in the aetiology of the condition because, as has been discussed previously, his patients had symptoms predominantly induced by bradycardia occurring at rest. The failure of his contemporaries to appreciate this point encouraged alternative theories to be put forward to explain the condition and as a result even Jenner's important observation was criticized by J. C. Warren (1778-1856), an American pathologist. Although Warren, following in the footsteps of his doctor father (John Warren), was aware of the pathophysiological significance of a massive pericardial effusion which had caused death due to cardiac tamponade, he could not understand why disease of the coronary arteries did not always produce symptoms and in an account of an autopsy he had performed he stated: " ... The coronary arteries at their origin from the aorta, and a considerable distance beyond, were ossified. How far does the existence of this ossification in this and other cases related by different authors, without the symptoms of angina pectoris, disprove the opinion that it is the cause of that disease? . ."..43

This contention was supported by his father's observation that angina could occur even when the coronary arteries were normal.4

Despite his excellent description of the symptoms of angina, Heberden, unlike Parry, did not relate the condition to the heart because the pulse was unchanged during an attack. One clue about his attitude towards Parry's work is in a letter from a Dr. Wall of Worcester which was read to the Royal College of Physicians. In this report, during angina the patient's pulse was "... never irregular but always small; 


\section{Brian Livesley}

and during the paroxysms, it sunk so small under the finger, that it could hardly be felt . ..".45 It was probably this observation which led Heberden to suspect that " . . . in cases of extremely low pulse, the artery beats oftener than it can be felt ... and some beats may not be sensible to the touch ..."46 and for this authoritative leader of the medical establishment to disregard Parry's ideas.

Although Parry's account was not published until 1799, his views had been made known earlier. He had presented details of one of his cases to The Fleece Medical Society in July $1788 .{ }^{47}$ In this he had been supported by Jenner's discovery of coronary arterial disease and his account of John Hunter's symptoms which were then well advanced. Unfortunately the issue was clouded when, three years later, it was suggested, in $A$ treatise on the disease commonly called angina pectoris, that the condition was due to diaphragmatic gout. ${ }^{48}$ At this time, the ever-ready diagnosis of gout was " . . . a great refuge in time of diagnostic difficulty . .." and there was even the “. . . tendency to call any malady not very clear, 'suppressed' gout . . ." ${ }^{49}$ The gouty origin of angina was supported in 1795, when a further case was described by Samuel Black, an Irish physician. ${ }^{50}$ This patient had experienced progressive angina on effort and died in left ventricular failure. Despite the demonstration at autopsy of "... the two coronary arteries exhibited the most complete ossification I ever saw ...", Black suggested that the symptoms had been due to diaphragmatic gout. Parry strenuously rejected this idea. However, in his turn Heberden resisted strongly Parry's concept of the syncope anginosa by including the symptoms of " . . giddiness, confusion, stupidity, inattention, forgetfulness and irresolution . . . . . they either sink under it in a fainting fit, or it is with great efforts and struggling they can keep from it. . .",51 under the heading of hypochondriacus et hystericus affectus. Contrary to their conflict of opinions, the terms angina pectoris and syncope anginosa became synonymous in British medicine for the next eighty years (1802-1882). The evidence for this is found in Quincy's Lexicon physico-medicum (1802), ${ }^{52}$ and Quain's Dictionary of medicine (1882), ${ }^{53}$ where the two conditions are linked together.

In 1809, Burns, a Glasgow anatomist and surgeon, wrote that anaemia of the myocardium, due to coronary obstruction ". . . must be a source of danger . . .".54 He supported Parry's concept but suggested that ". . . in the early part of the disease, the pulse is not so much affected . . . so complete as afterward ...".5 He suggested that Parry's patients had a more severe form of the same disease process which had affected Heberden's patients. Moreover, Burns' interpretation of the pathogenesis of the condition was influenced by his idea that, " . . . if there be actual dyspnoea present, you may be certain, that the disease is either not syncope anginosa, or that it is a complicated case, conjoined with . . . ossification of the valves. . ..".56

These comments are important because they highlight the problem which had prevented the physicians and pathologists from understanding the pathogenesis of angina because they were seeking a single cause. We now know that in some patients the simultaneous presence of two or more of the following conditions, anaemia, coronary arterial atheroma, valvar heart disease and hypertension may summate in their effects on the heart and each contribute towards the development of myocardial ischaemia when the heart is further stressed by tachycardiac or bradycardiac dysrhythm. 
Although Parry's book was translated and distributed on the Continent it produced no obvious immediate reaction. Even the great Corvisart did not describe ischaemic heart disease in his An essay on the organic disease and lesions of the heart and great vessels. ${ }^{57}$ This is probably because his major interest was in the effects of disease upon the heart valves which could itself provide sufficient evidence as to the causes of the pathophysiological changes he had studied previously at the bedside.

In England, the confusion between Heberden's and Parry's descriptions of angina persisted. In 1842, an awareness of the importance of the myocardial blood supply led Marshall Hall to suggest, “. . . Many facts induce me to believe, that the cases of sudden death [presumably, then as now, "sudden" meant "without previous symptoms"] arise chiefly from interruption of the coronary circulation! . ..".58 Furthermore, he suggested that disease of the coronary arteries was not the only factor which could be associated with impedance of coronary blood flow since ". . . In contracted aortal valve, in deficient mitral valve, in feeble ventricular impulse, ..." [my italics] $]^{59}$ all had similar effects and if the heart was suddenly paralysed under these circumstances " . . it may be suddenly arrested forever! . .." ${ }^{\circ 0}$ However, he limited the use of the term syncope anginosa to "... In some instances [my italics], this paralysis [of the heart] is not complete or permanent; and a peculiar transient, but a fearful state of syncope occurs hence the designation of syncope angens for this disease ...". ${ }^{61}$ However, Parry had, on the basis of limited experience, described all forms of angina pectoris as syncope anginosa.

Hall's work was supported by Burrows, a physician of St. Bartholomew's Hospital, London, who wrote On disorders of the cerebral circulation and on the connection between affections of the brain and diseases of the heart. ${ }^{62}$ However, in this same year, 1846, P. M. Latham produced his collected works and raised again the issue that " . . angina should germinate from the same root as gout is not unlikely ...", and Burrows' work does not appear to have been followed up. Indeed, the well-read French physician, Trousseau, ${ }^{\text {st }}$ did not comment about Burrows' work and although he did not refer to Parry either, it is obvious he had read about syncope anginosa since his account of the precipitating factors for angina is almost identical with that given by Parry. Trousseau's work is important to our study of the neglect of Parry's concept. In writing on angina from his own experience, Trousseau stated, “. . . But there is a predisposing cause, which cannot, I think be called in question, and which I have already mentioned, although no one has indicated it, namely epilepsy. In some cases, and perhaps in a pretty good number of instances, according to my experience, angina pectoris is an expression of this cruel and fearful complaint, and is a variety of the vertiginous form of the disease, in other words, it is an epileptiform neuralgia. Its invasion is as sudden, its progress as rapid and its disappearance as sudden, and as I have already told you, it is not of very uncommon occurrence to find persons who have in former years suffered from angina pectoris become subject afterwards to epileptic fits, just as in other instances angina pectoris has been preceded by wellmarked epileptiform seizures. ..". ${ }^{\mathrm{es}}$

This is a neurologist's account of syncope anginosa and he went on to advocate and justify the prescription of belladonna for patients with "epileptiform neuralgia"..8 This was the same remedy which forty years later Clifford Allbutt prescribed for 


\title{
Brian Livesley
}

similar patients and which has been supplanted today by the availability of artificial cardiac pacemakers. Another French physician, Jean-Martin Charcot, also described bradycardia and syncope in association with epilepsy but supported Butter's concept and ascribed angina pectoris to "... gout of the heart ...".67 He recognized that whatever title he used for the condition the outlook was invariably fatal. ${ }^{68}$ This was particularly important to him because he had already experienced his own first attack of angina after a dinner in the presence of Louis Pasteur. For the next two years he suffered severely not only with angina on effort but also spontaneous attacks at rest and episodes of fainting. His comments on "... the influence of gout on diseases of the heart ..."69 lead me to believe he was describing, at least in part, his own condition when he stated that,

\begin{abstract}
... in consequence, the physical signs are little characterized, and a diagnosis is reached above all by way of elimination [my italics].

The heartbeat is weak, almost nil; the first sound is muffled, and sometimes there exists a whistle occasioned by the fatty degeneration of the chordae tendineae. The precordial dullness is often augmented; the pulse is weak [my italics], depressible, intermittent, sometimes extremely slow, especially during the attack (20 or 30 pulsations) [Parry's syncope anginosa]; lastly, one has given a description of the presence of the arcus senilis (Canton) in subjects affected by this alteration in the muscular tissue of the heart.

The rational symptoms are well designed to trick the observer. The attacks develop by paroxysms; there are violent palpitations, dyspnoea, a syncopal tendency [Parry's syncope palpitans]; one sees some cerebral accidents which take the form of an apoplexy, although no intracranial haemorrhage were present (Law, Stokes). Some sharp pangs are [my italics] experienced in the precordial region, and radiate through the length of the arm, simulating angina pectoris, which itself is often considered an affection of gouty origin.

Finally sudden death is very frequent: thus in 83 cases of fatty degeneration reported by Quain, death took place in an unexpected manner 54 times, that is: 28 times by rupture of the heart, and 26 times by syncope. . . .
\end{abstract}

He suffered not only from Parry's syncope anginosa but also from Parry's syncope palpitans. Charcot obviously knew the true nature of his disease because while walking with a friend he asked him to slow down since he was unable to keep up with younger coronary arteries! In the early hours of one morning in 1893, Charcot developed acute pulmonary oedema and died. His international reputation as a teacher would have helped to spread the view that angina was due to gout of the heart especially when he was not only an excellent neurologist but also, being one of the first geriatricians, an expert on gout and other disorders of the locomotor system.

In 1897, when Osler produced his Lectures on angina pectoris and allied states, angina was not a common condition. ${ }^{71} \mathrm{He}$ stated that there had been only five cases out of the 8,868 medical patients who had attended Edinburgh Royal Infirmary in 1893/4. However, thirteen years later he had made notes on 268 cases he had seen ${ }^{72}$ and his definition of angina was, "... A disease characterized by paroxysmal attacks of pain, pectoral or extrapectoral, associated with changes in the arterial walls, organic or functional ...". ${ }^{73}$

Only five of his 268 patients had symptoms typical of Parry's angina. The vast majority of the remainder had Heberden's angina and although he did recognize that dissection of the aorta could simulate angina pectoris, he did not differentiate between Heberden's and Parry's types of angina. 


\section{The resolution of the Heberden-Parry controversy}

Little more was heard of syncope anginosa when in $1912 \mathrm{~J}$. B. Herrick, an American physician, described the clinical features of sudden obstruction of the coronary arteries. His reference to Parry's work was mainly to point to Jenner's discovery of diseased coronary arteries. ${ }^{74}$ Although we now regularly use the term "coronary thrombosis" which Herrick first coined, little attention was paid to this work at the time, and in England, Clifford Allbutt was putting forward Corrigan's idea of angina arising in the aorta. ${ }^{75}$ However, in his book, Allbutt described cases typical of those described by both Parry and Trousseau and, in fact, treated these patients successfully with atropine. ${ }^{76}$ The successful outcome of these cases added weight to what Allbutt put forward as his own concept of death from the condition being due to the effects of increased vagal tone, without giving due credit to Parry. Unfortunately, the aortic theory was so powerfully advocated by Sir Clifford Allbutt that his “. ... pre-eminent position, outstanding scholarship, and incisive style of writing succeeded in foisting his theory on many of the leading authorities in Europe ...".?7

When Herrick described his further experience with 250 cases of angina pectoris in 1918, he did not even mention syncope anginosa and suggested an aortic origin of the pain only in one patient aged forty years who had aortic incompetence. ${ }^{78}$ We now realize that this condition is more likely to be associated with angina due to a collapsing diastolic filling pressure of the coronary arteries as opposed to the vague aortic origin for angina put forward by Allbutt. One year later Herrick wrote again on coronary thrombosis and laid the foundations for the modern attitudes towards coronary thrombosis and atheroma. ${ }^{79}$ The present opinion that exhaustion of the heart muscle due to insufficient blood supply causes the symptoms of angina was underlined in 1923 by James Mackenzie ${ }^{80}$ and carefully restated in 1930 by Carey Coombs. ${ }^{81}$ However, angina pectoris had become no longer the major problem. The agonal states associated with myocardial infarction then, as now, attracted more attention. This highlights the almost impossible task confronting clinicians who have been, and still are, attempting to solve the problem of ischaemic heart disease. By the very nature of his work, the physician's attention is drawn too readily towards the patient's complaint of pain. This has distorted the understanding of the underlying pathophysiological processes because there is among patients considerable variation in pain complaint thresholds. ${ }^{82}$ Even today insufficient emphasis is placed upon this important aspect of the problem. Indeed, in patients who have syncope anginosa there is often no appreciation of pain by the patient during the process of fainting and because of this no awareness of the simultaneously occurring myocardial ischaemia by the physician (see Fig. 1).

It could be suggested that the absence of the electrocardiogram, invented in 1902, prevented Heberden and Parry from solving their controversy but this is not the case. Although in 1918 changes in the electrocardiogram had been observed during angina by Bousfield, ${ }^{83}$ the classical electrocardiographic sign of coronary arterial obstruction noted in $1920^{84}$ was, in fact, in a patient who had a form of syncope anginosa although this was neither recognized at the time nor had been commented upon elsewhere. Indeed, in 1939, syncope was ". . not a frequent symptom ..." and was accepted as "... a passage to death ...", the syncope lethalis. ${ }^{85}$ This work of G. Dock is a landmark in the history of ischaemic heart disease since it did not distinguish between the 


\section{Brian Livesley}

effects of acute and chronic occlusion of the coronary arteries. The confusion this created has persisted and the terms myocardial infarction, ischaemia, thrombosis, angina pectoris, and decubitus, are used synonymously by those who do not understand the different pathophysiological processes which distinguish these various conditions. Consequently, the correct separation of Heberden's from Parry's angina has not been possible through the years because Parry's concept of syncope has become misinterpreted and finally and conveniently labelled as the "syncope lethalis" and as a result "syncope anginosa" has become gradually neglected and, until now, forgotten. It is interesting to note that in 1959 a variant form of angina pectoris was described by Prinzmetal. ${ }^{86}$ This condition is typified by anginal attacks occurring at rest at an almost constant time of the day. In 1915 Allbutt had described such a patient in whom the attacks were prevented by oral atropine therapy. ${ }^{87}$. Indeed many, but not all, of the patients reported in the literature with this condition have, in fact, formes frustes of syncope anginosa. However, it is only now that other possible aetiological factors in Prinzmetal's variant form of angina can be more adequately studied because of the recent availability of techniques for pervenous cardiac biopsy and prolonged monitoring of cardiac ryhthm using a lightweight tape-recorder apparatus.

JOHN HUNTER'S POSTHUMOUS SOLUTION TO THE CONTROVERSY

Although Heberden had direct contact with John Hunter, Parry did not and consequently was unable to relate Hunter's symptoms to both Jenner's pathological discovery and his own observations on the pulse. The importance of this becomes clear when the pathophysiological basis of Hunter's illness is understood. It has been demonstrated that his anginal attacks occurred not only with presumed tachycardia consequent upon exertion [Heberden's angina] but also, and most severely during the attacks of pronounced bradycardia which occurred at rest [Parry's angina] and which may have developed in response to emotional stress. In John Hunter's case; the onset of prolonged and severe bradycardia aggravated the effects of certainly aortic and probably too mitral stenosis and resulted in hypoperfusion of the coronary and cerebral arteries thereby producing syncope anginosa. ${ }^{88}$

\section{CONCLUSION}

The religious issue which by a rule of Charles II, prevented non-conformists from being admitted to the College of Physicians as Fellows helped to create bitter attitudes between Establishment and Dissenting physicians. Such was the relationship between Heberden and Parry.

From the information which has been provided above, we can see that as a result of their detailed observations on only a few patients, Heberden and Parry between them had all the information necessary to discover that they were each describing different aspects of the syndrome of ischaemic heart disease. Parry's concept became neglected for the reasons discussed. The resolution of the Heberden-Parry controversy has only been possible now because of the availability of radiotelemetric electrocardiography and the development of a precise method for studying myocardial lactate extraction. In my experience, today Parry's angina only accounts for some 


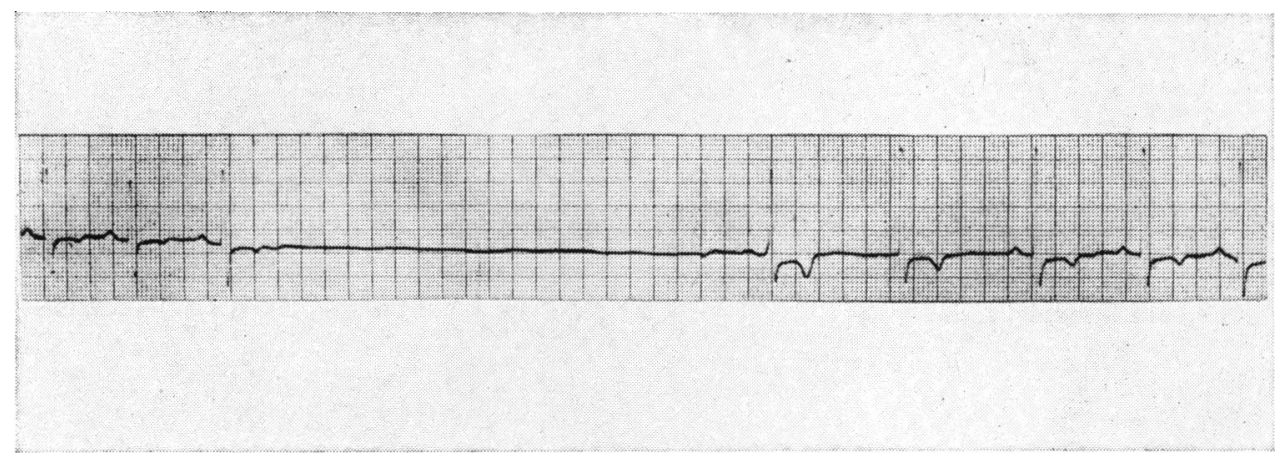

Figure 1.

The patient experienced severe lightheadedness during a period of sinuatrial block recorded on the electrocardiogram. The resumption of sinus rhythm with transient pronounced S-T segment and T-wave depression demonstrates the asymptomatic myocardial ischaemia which had occurred during this period. 


\section{The resolution of the Heberden-Parry controversy}

five to ten per cent of patients with angina pectoris. This is presumably because severe coronary arterial atherosclerosis, resulting in the predominance of Heberden's angina, has become the major problem as a result of the increasing average age and vastly improved nutritional status within our society. Parry's syncope anginosa, or syncope angens as he later called it, now presents most commonly in the elderly and in a different guise. In this group of patients, repeated falls, strokes and sometimes dementia are being generally unrecognized for the attacks of syncope anginosa they represent. ${ }^{89}$

\section{ACKNOWLEDGEMENTS}

I am grateful to Dr. Samuel Oram for providing the stimulating environment in which most of these thoughts took root and to Dr. Kenneth Keele for his constructive criticism of the MS. Thanks are also due to Eric Gaskell, former Librarian of the Wellcome Institute for the History of Medicine and Miss Gillian M. Pentelow, Librarian, King's College Hospital Medical School.

\section{REFERENCES}

1. Jean-Martin Charcot, Clinical lectures on senile and chronic diseases, trans. by Leigh $\mathbf{H}$. Hunt, New York, Wood, 1881, p. 1.

2. William Heberden, 'Some account of a disorder of the breast', Med. Trans. Coll. Phys. Lond., 1772, 2: 59-67.

3. Caleb H. Parry, An inquiry into the symptoms and causes of the syncope anginosa, commonly called angina pectoris, Bath, Cruttwell, 1799, p. 2.

4. Norman J. Holter, 'Radioelectrocardiography: A new technique for cardiovascular studies', Ann. N.Y. Acad. Sci., 1957, 65: 913-923.

5. Brian Livesley and Samuel Oram, 'Diagnosis of doubtful angina: comparison of the radiotelemetric exercise electrocardiogram with the lactate content of coronary sinus blood after pacing', Lancet, 1973, i: 1461-1465.

6. Ibid., pp. 1464-1465.

7. Brian Livesley, Patricia F. Catley, Robert C. Campbell and Samuel Oram, 'Doubleblind evaluation of verapamil, propranolol and isosorbide dinitrate against a placebo in the treatment of angina pectoris', Br. med. J., 1973, i: 375-378.

8. Op. cit., note 2 above, pp. 59-60.

9. However, we now know that Heberden's angina can also occur in patients with normal coronary arteries! This apparent paradox has been explained recently by the discovery that in these patients tachycardiac myocardial ischaemia occurs in the presence of a cardiomyopathy.

10. Op. cit., note 5 above, p. 1465.

11. Op. cit., note 7 above, p. 376.

12. Henry P. Bowditch, Uber die Eigenthumlichkeiten der Reizbarkeit, welche die Muskelfasern des Herzens zeigen', Arb. physiol. Anft. Leipz. (1871), 1872, 6: 139-176.

13. Brian Livesley, 'The use of the Bowditch effect for the successful management of artificial pacemaker therapy', Mod. Geriat., 1972, 2: 164.

14. Brian Livesley, Patricia F. Catley and Samuel Oram, 'Familial sinuatrial disorder', Br. Heart J., 1972, 34: 668-670.

15. Brian Livesley, 'The spasms of John Hunter: A new interpretation', Med. Hist., 1973, 17: 70-75.

16. Ibid., pp. $72-74$.

17. Timothy Leary, 'Pathology of coronary sclerosis', Amer. Heart J., 1935, 10: 328-337.

18. William Heberden, Commentaries on the history and cure of diseases, London, T. Payne, 1802 , pp. $365-366$.

19. Thomas Lewis, 'Caleb Hillier Parry', Proc. Cardiff med. Soc., 1941, Session 1940-1: 71-89. 


\section{Brian Livesley}

20. Duncan C. L. Fitzwilliams, 'Caleb Hillier Parry', Med. Wld, Lond., 1946, 65: 44-47.

21. Thomas H. Bishop, 'Caleb Hillier Parry, 1755-1822', Med. Press, 1955, 234: 401-402.

22. Op. cit., note 3 above, p. 67.

23. Giovanni B. Morgagni, De sedibus, et causis morborum, Venice, Remondiniana, 1761, vol. 1, p. 282. Cited by Caleb Hillier Parry, op. cit., note 3 above, pp. 46 and 48.

24. Op. cit., note 3 above, pp. 7-8.

25. Ibid., p. 14.

26. Ibid., p. 14.

27. Ibid., pp. 17-18.

28. Ibid., p. 18.

29. Ibid., p. 18.

30. Ibid., p. 28.

31. Ibid., p. $47 .$.

32. Ibid., pp. 48-49.

33. Ibid., p. 60.

34. Ibid., pp. $3-4$.

35. Ibid., p. 108.

36. Ibid., p. 102. Here, one wonders if Parry meant carotid sinus compression, since earlier in his account he had noted that carotid pressure reduced the heart rate of Admiral K. S. by 15-20 beats/min. Moreover, he used to advocate this treatment to relieve migraine from which he himself suffered and one can only speculate that this manoeuvre caused the right hemiplegia which he later developed.

37. Ibid., pp. 140-141.

38. Ibid., p. 57.

39. Op. cit., note 18 above, p. 367.

40. Op. cit., note 3 above, pp. 68, 77 and 122.

41. Ibid., pp. 143-144.

42. Clifford Allbutt, Disease of the arteries including angina pectoris, vol. 2, London, Macmillan, 1915, vol. 2, pp. 406-408.

43. John C. Warren, Cases of organic disease of the heart, Boston, 1809, p. 52.

44. John Warren, 'Remarks on angina pectoris', New Eng. J. Med. Surg., 1812, 1: 1-11.

45. William Heberden, 'A letter from Dr. Wall to Dr. Heberden on the same subject', Med. Trans. Coll. Phys. Lond., 1785, 3: 12-24.

46. Thomas J. Pettigrew, 'William Heberden' in Medical portrait gallery, London, Whittaker, 1840, 3 : 14.

47. Op. cit., note 3 above, pp. 2 and 5.

48. William Butter, $A$ treatise on the disease commonly called angina pectoris, London, J. Johnson, 1791, p. 36.

49. John M. Fothergill, Diseases of sedentary and advanced life, London, Ballière, Tindall \& Cox, 1885, p. 190.

50. Samuel Black, 'Case of angina pectoris with remarks', Mem. Med. Soc. Lond., 1795, 4: 261-279.

51. Op. cit., note 18 above, p. 226.

52. Robert Hooper, ‘Angina Pectoris', in John Quincy's Lexicon physico-medicum, London, T. Longman, 1802.

53. Richard Quain, Dictionary of medicine, London, Longmans, 1882, part 1, p. 50.

54. Allan Burns, Observations on some of the most frequent and important diseases of the heart, Edinburgh, Bryce, 1809, p. 139.

55. Ibid., p. 144.

56. Ibid., pp. 140-141.

57. Jean N. Corvisart, An essay on the organic diseases and lesions of the heart and great vessels, trans. by Jacob Gates, Boston, 1812.

58. Marshall Hall, The mutual relations between anatomy, physiology, pathology and therapeutics and the practice of medicine, London, Baillière, 1842, p. 55. 


\section{The resolution of the Heberden-Parry controversy}

59. Ibid., p. 56.

60. Ibid., p. 56.

61. Ibid., p. 57.

62. George Burrows, On disorders of the cerebral circulation and on the connection between affections of the brain and disease of the heart, London, Longman, 1846, pp. 105-125.

63. Peter M. Latham, The collected works, ed. Robert Martin, London, New Sydenham Society, 1876, vol. 1, p. 480.

64. Armand Trousseau, Lectures on clinical medicine, trans. by P. Victor Bazire, London, New Sydenham Society, 1868, vol. 1, pp. 602-611.

65. Ibid., p. 602.

66. Ibid., p. 611.

67. Op. cit., note 42 above, pp. 231 and 522.

68. Jean-Martin Charcot, Leçons cliniques sur les maladies des vieillards et les maladies chroniques, Paris, Adrien Delahaye, 1867, p. 85.

69. Ibid., p. 84.

70. Ibid., pp. 84-85.

71. Sir William Osler, Lectures on angina pectoris and allied states, Edinburgh, Pentland, 1897.

72. Sir William Osler, 'The Lumleian lectures on angina pectoris', Lancet, 1910, i: 697-702 and 839-844.

73. Ibid., p. 697.

74. James B. Herrick, 'Clinical features of sudden obstruction of the coronary arteries', J. Amer. med. Ass., 1912, 39: 2015-2020.

75. Sir Dominic J. Corrigan, 'Aortitis as one of the causes of angina pectoris with observations on its nature and treatment', Dublin J. med. Sci., 1837-8, 12: 243-354.

76. Op. cit., note 42 above, pp. 227-230, 246, 485 and 522.

77. Davis E. Bedford, 'William Heberden's contribution to cardiology', J. Roy. Coll. Phys. Lond., 1968, 2: 134-135.

78. James B. Herrick and Frank R. Nuzum, 'Angina pectoris; clinical experience with 200 cases', J. Amer. med. Ass., 1918, 70: 67-70.

79. James B. Herrick, 'Thrombosis of the coronary arteries', ibid., 1919, 72: 387-390.

80. Sir James Mackenzie, Diseases of the heart, London, Oxford University Press, 1925, p. 335.

81. Carey F. Coombs, 'Observations on the aetiological correspondence between anginal pain and cardiac infarction', Quart. J. Med., 1930, 23: 233-240.

82. Kenneth D. Keele, 'Pain complaint threshold in relation to pain of cardiac infarction', Br. med. J., 1968, i: 670-673.

83. Guy W. J. Bousfield, 'Angina pectoris: changes in E.C.G. during a paroxysm', Lancet, 1918, ii: 457-458.

84. Harold E. B. Pardee, 'An electrocardiographic sign of coronary arterial obstruction', Arch. int. med., 1920, 26: 244-257.

85. George Dock, 'Historical notes on coronary occlusion', J. Amer. med. Ass., 1939, 113: 563-568.

86. Myron Prinzmetal, Rexford Kennamer, Reuben Merliss, Takashi Wada and Naci Bor, 'Angina pectoris: 1. A variant form of angina pectoris', Amer. J. Med., 1959, 27: 375-388.

87. Op. cit., note 42 above, pp. 229-230.

88. Op cit., note 15 above.

89. Brian Livesley and Lynne Atkinson, 'Repeated falls in the elderly', Mod. Geriat., 1974, 4: 458-467. 